Journal of Chemical \& Engineering Data- Accepted Manuscript- je-2019-00026s.R5

October 2019

\title{
Surface tension of aqueous solutions of small-chain amino and organic acids
}

\author{
Mohsin Ali Raza ${ }^{1}$, Paul D. Hallett,Xiangyang Liu, Maogang He, Waheed Afzal
}

\begin{abstract}
Surface tension was measured for aqueous solutions of DL-malic acid, L-glutamine, L-serine, L-proline, L-methionine, L-valine, and L-lactic acid as a function of concentration using a $\mathrm{Du}$ Noüy ring over a temperature range between $298 \mathrm{~K}$ and $328 \mathrm{~K}$ at $101 \mathrm{kPa}$ atmospheric pressure. Surface tensions of several concentrations of each organic acid were measured to develop four isotherms with a temperature ramp of $10 \mathrm{~K}$ starting from $298 \mathrm{~K}$. Cohesive forces between molecules were weakened by temperature rise, resulting in decreased surface tension. Mass concentration and temperature effects on surface tension were reflected by the slopes of the relationships between surface tension and either mass concentration or temperature, respectively. In this study L-serine and L-glutamine showed hydrophilic behaviour while Lproline, L-methionine, DL-malic acid, L-valine, and L-lactic acid had hydrophobic behaviour. For all acids studied here, increased temperature caused decreased surface tension of aqueous solutions of solute.
\end{abstract}




\section{Introduction}

Surface tension is the change in Gibbs free energy per unit change in interfacial area for two immiscible phases such as liquid-gas ${ }^{1}$. Surface tension defines the extent of mass transfer from one phase to another. This work has studied five amino acids having an alkyl, carboxylic functional group with amine group and two organic acids replacing amine with hydroxyl group. They are important in many biological processes. For example, in plants, organic acids and amino acids are secreted by plant roots to improve resource capture from surrounding soil. Some plant seeds also produce surface coating agents with chemical functionalities similar to these compounds to aid in germination and counter environmental stresses such as water deficiency in drought conditions ${ }^{2}$. Furthermore, the thermodynamic data such as surface tension data of aqueous solutions of small-chain amino and organic acids are important for pharmaceuticals and food industries to improve design and operation of the unit operations as surface tension and volumetric properties are vital for understanding the multi-fluid phase transport processes ${ }^{3}$.

Chemical characterization of organic compounds released into soil by plants found organic and amino acids to differ between species, with glycine, valine, alanine, isoleucine, and theonine forming major components ${ }^{4}$. On natural compounds harvested from the exudates of growing roots or mucilage of hydrated seeds, Naveed et al. detected large differences between plant species in surface activity and rheological behaviour, which they attributed to chemical components ${ }^{4}$ similar to those studied in this work. To date, however, the contribution of the individual chemical components to physical behaviour of biological exudates and mucilages from plants are not known. An understanding of the physical behaviour of these compounds produced by plants could help in selecting new crop varieties that capture resources more effectively from soils. Moreover, fertiliser dispersal and uptake could be improved by adding these compounds to soils, and there may be use in industrial applications involving natural products $^{5}$. Our ongoing studies of several chemicals including individual amino acids provide a potential model framework to define the behaviour of exudates and mucilages depending upon composition and concentration of amino acids ${ }^{6-8,9}$.

Several studies ${ }^{9-11}$ have been conducted in the literature to observe the behaviour of amino acids in aqueous solutions with salts. The thermodynamic properties of small chain amino acids and organic acids underpin their hydrophobic and hydrophilic nature, with such data useful to the interpretation of the behaviour of systems containing a mix of compounds such as plant 
mucilage and exudates. However, surface tension available in the literature for organic acids studied here in their respective aqueous solution at different temperatures is scarce. These data are also restricted by being studied on or near ambient conditions ${ }^{10,11}$, with the effect of temperature on surface tension of amino acids rarely studied ${ }^{9}$.

Belton and Twidle ${ }^{11}$ studied the surface tension of a few amino acids as a function of $\mathrm{pH}$ in the presence of an acid, an alkali, and a salt. They ${ }^{11}$ found that glycine and alanine caused increase in surface tension water. Cystine, valine and hippuric acid caused decrease in surface tension of water. Another study by Bull and Breese developed a hydrophobicity scale using the free energies of the residue of amino acids transferred from solution to the interface ${ }^{12}$. In surface tension curves, the influence of amino acid concentration on the development of hydrophobic or hydrophilic behaviour of amino acids describes the dominant interaction of solute molecules on the surface ${ }^{12-15}$. Hyvärinen et $\mathrm{al}^{11}$ reported surface tension data for aqueous solutions of malic acid at room temperature over a range of concentration. Rodríguez et $\mathrm{al}^{9}$ studied surface tension of glycine and alanine aqueous solutions at sub-ambient air pressure of $75 \mathrm{kPa}$ and temperatures of to $313.15 \mathrm{~K}$.

This study measured the surface tensions of L-glutamine, L-serine, L-methionine, L-proline, L-valine, L-lactic acid or DL-malic acid aqueous solutions over a range of concentrations from 298-328 $\mathrm{K}$ and ambient pressure of $101 \mathrm{kPa}$. The effects of solute concentration and temperature were studied for each compound, producing relationships useful to describing behaviour under a wide range of conditions.

\section{Materials and Methods}

Table 1 shows the list of chemicals used in this study with their CAS and supplier details.

The surface tension of our acid solutions was measured with Attension Sigma 701 Force Tensiometer using the Du Noüy ring supplied by Biolin Scientific. This method measures the force exerted by the meniscus on the Du Noüy ring to determine the surface tension of the fluid/liquid. The accuracy of the tensiometer allows a measure of surface tension to 0.001 $\mathrm{mN} / \mathrm{m}$ with the weight resolution to $0.01 \mathrm{mg}$ as per manufacturers. The tensiometer calibration was first verified using 5 and $10 \mathrm{~g}$ standard weights.

The $\mathrm{pH}$ of the initial aqueous solutions of all acids were measured using Thermo Scientific ${ }^{\mathrm{TM}}$ Orion $^{\mathrm{TM}}$ Versa star advanced electrochemistry meter with relative accuracy up to \pm 0.002 . Density of these initial solutions were also measured using Anton Paar DMA 4100M. 
The temperature was maintained at $\pm 0.1 \mathrm{~K}$ in our work, measured with a temperature probe having resolution up to three decimal places. The temperature of solution sample was maintained using a water bath assembly consisting of Thermo Haake C10 immersion circulator having rated temperature range between $293.15 \mathrm{~K}$ and $343.15 \mathrm{~K}$ with temperature stability within the temperature control mentioned earlier. Temperature sensor (Pt-100) was installed to record data along with surface tension the automated online acquisition system preinstalled on the tensiometer by its manufacturer. The solution was stirred between surface tension measurements to maintain the homogeneity and temperature distribution throughout the sample solution. Significant residence time was provided between stirring and taking the reading under still conditions.

The surface tension measurements obtained in this work were checked using NanoPure water at four working temperatures and compared with the reliable literature data ${ }^{16}$. This water had better than 18.2 megaohm ionic purity. Solutions were prepared gravimetrically using a Sartorius Secura324-1S analytical laboratory mass balance that was accurate to $0.1 \mathrm{mg}$ and calibrated regularly. Mass percent uncertainties for L-methionine, DL-malic acid, L-serine, Lglutamine, L- proline, L-valine and L-lactic acid were, $\pm .002, \pm .005, \pm .001, \pm .001, \pm .005$, \pm .001 , and $\pm .002 \mathrm{~g}$ respectively. Experimental uncertainties on mole fraction estimated $\pm 0.0002 \mathrm{~g}$. Measurements were carried out in a $220 \mathrm{ml}$ wide glass beaker that was half-filled with the solutions to a volume $110 \mathrm{ml}$. Before usage, the beaker was washed with detergent, rinsed with double deionized water and ethanol. After rinsing, the beaker was dried in an oven at $383 \mathrm{~K}$. Surface tension was measured using a platinum Du Noüy ring which was washed after every measurement with ethanol and then dried in a flame at a temperature over $1100 \mathrm{~K}$ to ensure a clean surface of the ring for the next reading. During the measurements, vibrations were avoided to produce accurate results. Each reported surface tension value is the average of at least 3 measurements, with the relative standard deviation (coefficient of variation) less than $0.001 \mathrm{mN} / \mathrm{m}$. The standard error of the surface tension measurements is presented.

Concentration ranges of most solutes in their aqueous solutions are selected based on the limiting solubilities; five or six different concentrations of each solute are studied at four isotherms. However malic acid concentrations were restricted to stay in the close possible range to other acids studied here for a reasonable comparison. Malic acid has already been studied in the literature with a bigger concentration gradient to cover the solubility range ${ }^{11}$. 
To verify the reliability of the surface tension results, we measured surface tension of water to compare it with the literature ${ }^{16}$. We also measured surface tension of aqueous solutions of ethanol over a range of concentrations and compared it with the literature ${ }^{17}$. The deviations between our data with both of the standard data sets in references ${ }^{16,17}$ were found within their experimental uncertainties $\leq 0.4 \mathrm{mN} / \mathrm{m}$. Based on these experiments, we labelled our experimental uncertainty $\leq 0.5 \mathrm{mN} / \mathrm{m}$. Ethanol-water surface tension results are shown in Table 2 and graphical comparison is presented in Figure 1. Based on the standard error of the mean for our triplicates, our reproducibility was found much better than overall estimated uncertainty for our surface tension data.

\section{Results and Discussion}

Experimental surface tension data for all the seven acids in aqueous solutions at temperatures between $293 \mathrm{~K}$ and $328 \mathrm{~K}$ with $10 \mathrm{~K}$ temperature differences are presented in this section. Table 3 through 7 report the surface tension dependence of amino acids with mass \% concentration at $\mathrm{T}=298,308,318$ and $328 \mathrm{~K}$. Table 12 shows the density and pH measurements of initial concentrations of amino and organic acids studied in this work.

Figures $2,4,6,8,10,12$, and 14 show the effect of concentration on surface tension at four different temperatures. The surface tension of L-methionine and L-proline decreased slightly with increasing concentration. DL-malic acid, L-valine and L-lactic acid had a significant decrease in surface tension with increasing concentration. The surface tensions of L-serine and L-glutamine aqueous solutions, on the other hand, increased with increasing concentration. Similar behaviour was observed at all temperatures. Surface tension data of DL-malic acid presented in this work agrees with data in the literature and follows a similar trend with changing concentration in an aqueous solution ${ }^{11}$.

Figures 3, 5, 7, 9, 11,13 and 15 show the temperature effect on surface tension. Surface tension of all of the amino acid solutions was very dependent of temperature. As expected, the rise in temperature caused a decrease in surface tension of all amino acids. This result was anticipated because the increase in temperature caused a decrease in the intermolecular forces, thereby decreasing surface tension for studied systems.

Standard errors of mean for our triplicates for which the mean values are reported in the data tables all these results are in a narrow range: $0.01 \geq \mathrm{S}$.E $\geq 0.02$ for L-methionine, DL-malic acid, L-serine, L-proline, and L-lactic acid, and $0.01 \geq$ S.E $\geq 0.04$ for L-glutamine, and Lvaline. A correlation for the surface tension of aqueous solutions of L-methionine, DL-malic 
acid, L-serine, L-glutamine, L-proline, L-valine, and L-lactic acid is proposed based on the trend between surface tension, temperature and concentration, expressed in eq. 1

$$
\sigma=a+b T+(c+d T) m \quad \text { eq. } 1
$$

where $\mathrm{a}, \mathrm{b}, \mathrm{c}$, and $\mathrm{d}$ are coefficients regressed on our experimental data, and $m$ is the mole fraction of the studied acids in aqueous solution. The eq. 1 is useful for the presentation of the data; no effect is made to establish any physical meanings of the constants a, b, c, and d. The fitted coefficients are listed in Table 11 along with the average absolute relative deviations (AARD) and the maximum absolute relative deviations (MARD). Some statistical definitions expressed in eq. 2 used for the evaluation of correlation.

$$
\mathrm{AARD}=\frac{\sum\left|\sigma_{\text {experimental }}-\sigma_{\text {correlation }}\right|}{N \sigma_{\text {experimental }}} \text { eq. } 2
$$

The correlations of the surface tensions of aqueous solutions of L-methionine, DL-malic acid, L-serine, L-glutamine, L-proline, L-valine and L-lactic acid have an AARD less than 0.33\% and an MARD less than $1.07 \%$. The calculated results from the correlations are also presented in Figures 2-15, which shows a good agreement with the experimental data.

The slopes of surface tension as a function of mass percent concentration shown in Table 10 reflects the nature of solute and can be used to classify the solutes based on predominant interactions with water. In this case, L-serine and L-glutamine show positive slopes reflecting the hydrophilic nature of solutes, whereas L-methionine, L-proline, DL-malic acid, L-valine, and L-lactic acid exhibits negative slopes which shows the hydrophobic behaviour of the solutes in water.

Among organic acids L-lactic acid reflects highest value of negative slope in Table 10 as compare to DL-malic acid. L-lactic acid contains one carboxylic group linked with two hydroxyl and one methyl group offering strong interactions with water molecules and reflects strong hydrophobic nature of the solution. In case of amino acids L-proline doesn't show any promising change in the surface tension of aqueous solution in comparison to other amino acid. L-proline contains a cyclic organic molecule with one amine group in it and doesn't interact much with water molecules in binary mixture. L-glutamine and L-serine contains no methyl group in its carbon chain and mostly carbon atoms are linked with amine or hydroxyl group which causes increase in surface tension of aqueous solutions. L-methionine and L-valine contains one and two methyl groups in its chain respectively. 


\section{Conclusion}

This study found that L-methionine, DL-malic acid, L-serine, L-glutamine, L-proline, L-valine and L-lactic acid had different behaviour in aqueous solutions depending upon the presence of alkyl chains and its interaction with water. Amino acid with more methyl groups causes decrease in surface tension by increasing the intermolecular forces and reflects strong hydrophobic behaviour of aqueous solutions. All amino acids have five carbons except L-serine and L-valine. L-methionine L-proline, and L-valine, which have one carboxylic group and one amine group showing hydrophobic behaviour in aqueous solution. L-glutamine also have five carbons but with two carboxylic and amine groups. DL-malic acid and L-lactic acid are organic acids and show hydrophobic behaviour in water. All amino and organic acids studied, except L-serine and L-glutamine present in plant exudates, show hydrophobic behaviour in aqueous solutions, therefore not having any strong hydrophilic behaviour in water. The results also show that temperature change only creates a step change in surface tension of the solution to a new value, while the trend and behaviour for each amino acid remains the same. 


\section{References}

1) Shahid, M.Z., Usman, M.R., Akram, M.S., Khawaja, S.Y. and Afzal, W. Initial Interfacial Tension for Various Organic-Water Systems and Study of the Effect of Solute Concentration and Temperature. J. Chem. Eng. Data, 2017, 62, pp.1198-1203.

2) Gregory, P.J., Bengough, A.G., George, T.S., Hallett, P.D. Rhizosphere engineering by plants: quantifying soil-root interactions. In: Timlin D and Ahuja L (eds), Enhancing understanding and quantification of soil-root growth interactions, American Society of Agronomy, Crop Science Society of America, Soil Science Society of America, Madison, 2013 pp.1-30.

3) Afzal, W., Valtz, A., Coquelet, C. and Richon, D. Volumetric properties of (piperidine+ water) binary system: Measurements and modeling. J. Chem. Thermodyn., 2008, 40, pp.4753.

4) Naveed, M., Brown, L.K., Raffan, A.C., George, T.S., Bengough, A.G., Roose, T., Sinclair, I., Koebernick, N., Cooper, L., Hackett, C.A. and Hallett, P.D. Plant exudates may stabilize or weaken soil depending on species, origin and time. Eur. J. Soil Sci., 2017, 68, pp.806-816.

5) Deng, W., Iannetta, P.P., Hallett, P.D., Toorop, P.E., Squire, G.R. and Jeng, D.S. The rheological properties of the seed coat mucilage of Capsella bursa-pastoris L. Medik.(shepherd's purse). Biorheology, 2013, 50, pp.57-67.

6) Likhodi, O. and Chalikian, T.V. Partial molar volumes and adiabatic compressibilities of a series of aliphatic amino acids and oligoglycines in $\mathrm{D}_{2}$ O.J. Am. Chem. Soc., 1999, 121, pp.1156-1163.

7) Zhao, H. Viscosity B-coefficients and standard partial molar volumes of amino acids, and their roles in interpreting the protein (enzyme) stabilization. Biophys. Chem., 2006, 122, pp.157-183.

8) Oleghe, E., Naveed, M., Baggs, E.M. and Hallett, P.D. Plant exudates improve the mechanical conditions for root penetration through compacted soils. Plant Soil, 2017, 421, pp.19-30.

9) Rodríguez, D.M. and Romero, C.M. Surface tension of glycine, alanine, aminobutyric acid, norvaline, and norleucine in water and in aqueous solutions of strong electrolytes at temperatures from (293.15 to 313.15) K. J. Chem. Eng. Data, 2017, 62, pp.3687-3696. 
10) Belton, J.W. and Twidle, A.H.H. The surface tensions of amino-acid solutions as a function of p H. Trans. Faraday Soc., 1940, 36, pp.1198-1208.

11) Hyvärinen, A.P., Lihavainen, H., Gaman, A., Vairila, L., Ojala, H., Kulmala, M. and Viisanen, Y. Surface tensions and densities of oxalic, malonic, succinic, maleic, malic, and cispinonic acids. J. Chem. Eng. Data, 2006, 51, pp.255-260.

12) Romero, C.M., Jiménez, E. and Suárez, F. Effect of temperature on the behaviour of surface properties of alcohols in aqueous solution. J. Chem. Thermodyn., 2009, 41, pp.513-516.

13) Bull, H.B. and Breese, K. Surface tension of amino acid solutions: a hydrophobicity scale of the amino acid residues. Arch. Biochem. Biophys., 1974, 161, pp.665-670.

14) Romero, C.M. and Paéz, M.S. Surface tension of aqueous solutions of alcohol and polyols at 298.15 K. Phys. Chem. Liq., 2006, 44, pp.61-65.

15) Cadena, J.C. and Romero, C.M. Effect of temperature on the surface properties of $\alpha, \omega-$ amino acids in dilute aqueous solutions. J. Therm. Anal. Calorim., 2016, 126, pp.1615-1619.

16) Vargaftik, N.B., Volkov, B.N. and Voljak, L.D. International tables of the surface tension of water. J. Phys. Chem. Ref. Data, 1983, 12, pp.817-820.

17) Vazquez, G., Alvarez, E. and Navaza, J.M. Surface tension of alcohol water+ water from 20 to $50^{\circ}$ C. J. Chem. Eng. Data, 1995, 40, pp.611-614. 


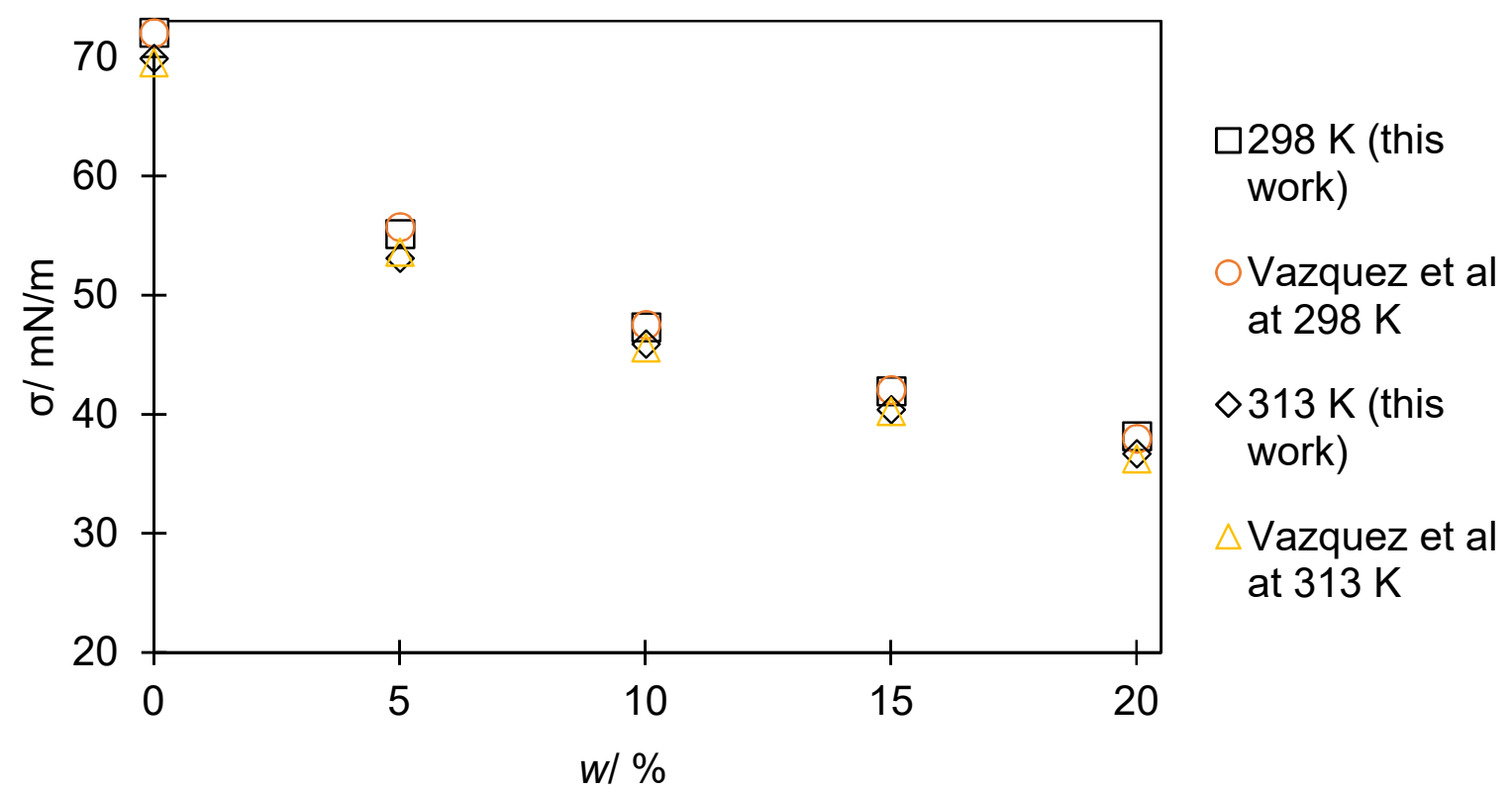

Figure 1: Comparison between our data and those from ${ }^{14}$ to show concentration $w / \%$ effect on surface tension $\sigma$ of ethanol- water binary system at two temperatures $T$ and pressure $p=101 \mathrm{kPa}$. The absolute deviation between two data sets is less than 0.5 $\mathrm{mN} . \mathrm{m}$.

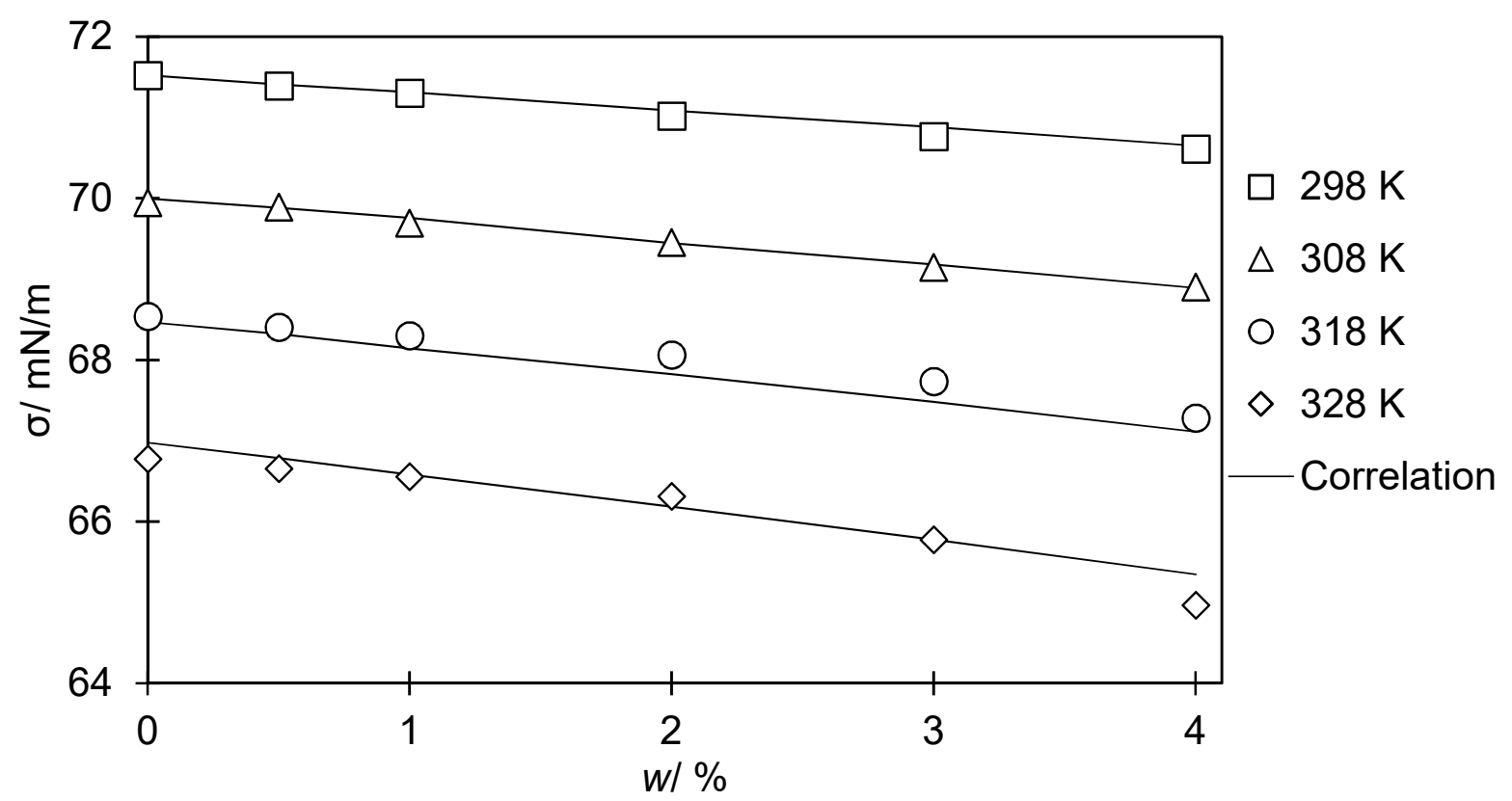

Figure 2: Concentration $w / \%$ effect on surface tension $\sigma$ of L-methionine from $T=$ $(298-328) \mathrm{K}$ at $p=101 \mathrm{kPa}$, the fitted line is from correlation and statistical results from correlation analysis are listed in Table 11. 


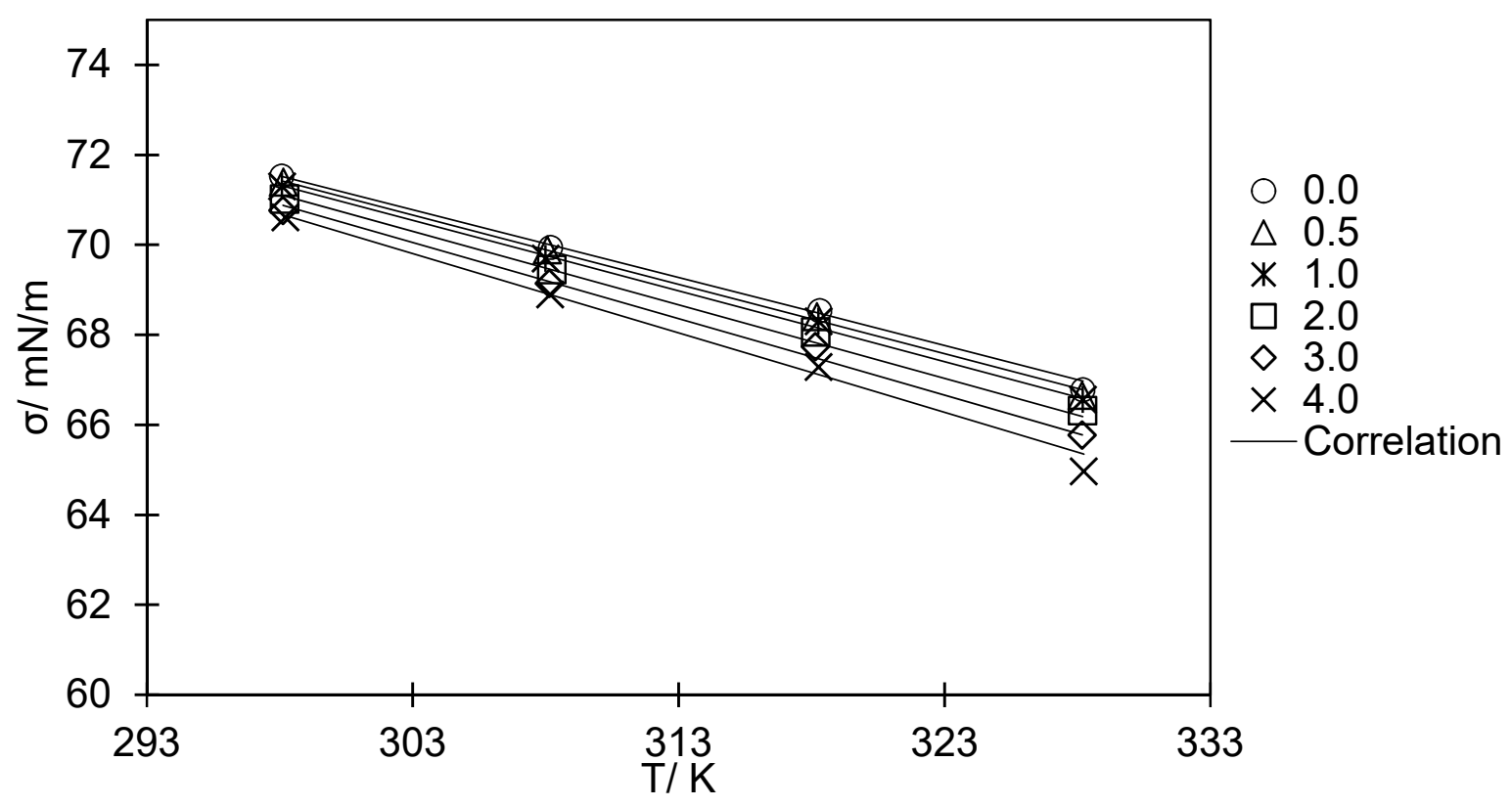

Figure 3: Temperature $T$ effect on surface tension $\sigma$ of L-methionine at different concentrations $w / \%$, the fitted line is from correlation and statistical results from correlation analysis are listed in Table 11.

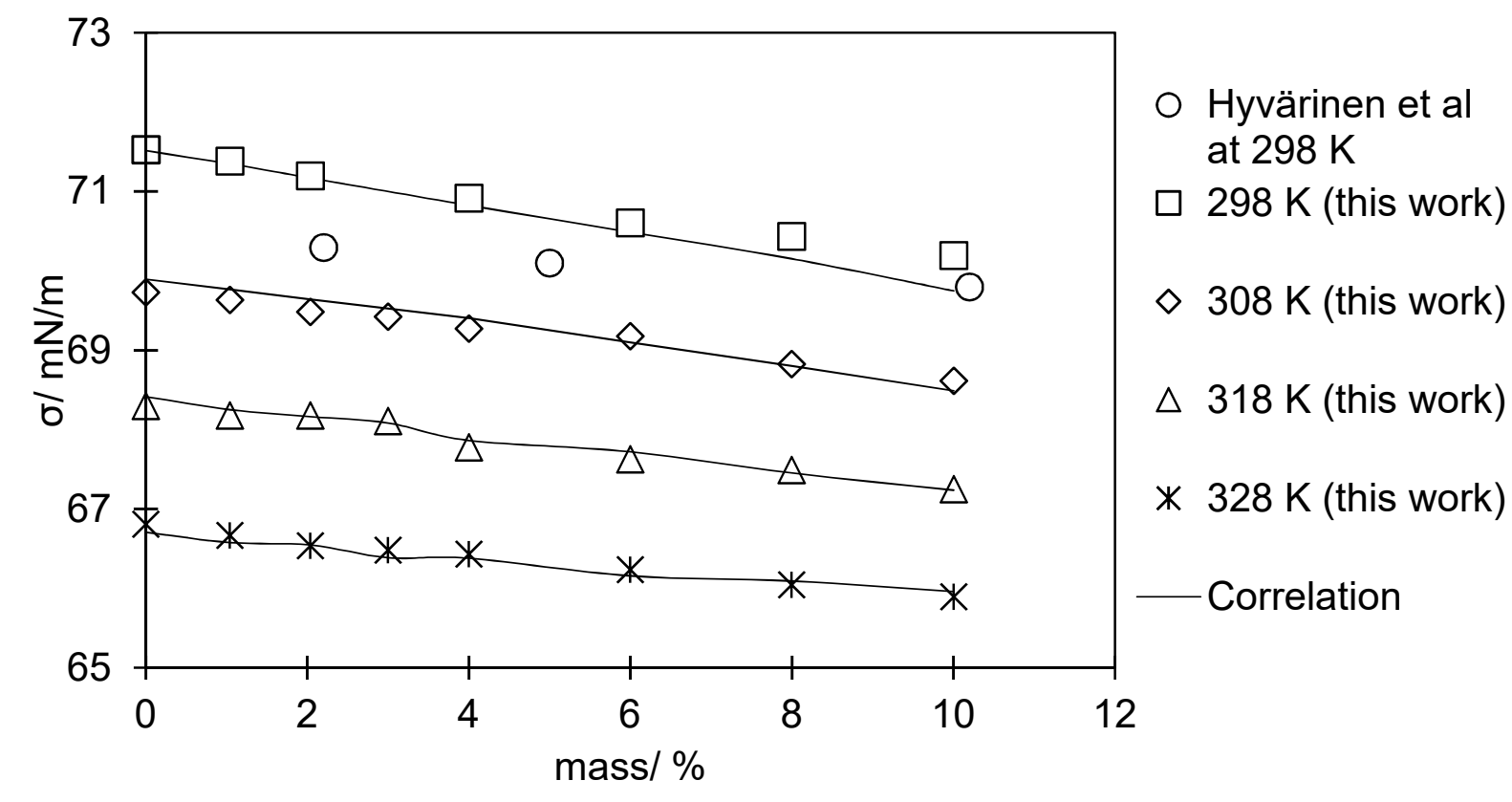

Figure 4: Concentration $w / \%$ effect on surface tension $\sigma$ of DL-malic acid from $T=$ $(298-328) \mathrm{K}$ at $p=101 \mathrm{kPa}$, the fitted line is from correlation and statistical results from correlation analysis are listed in Table 11. 


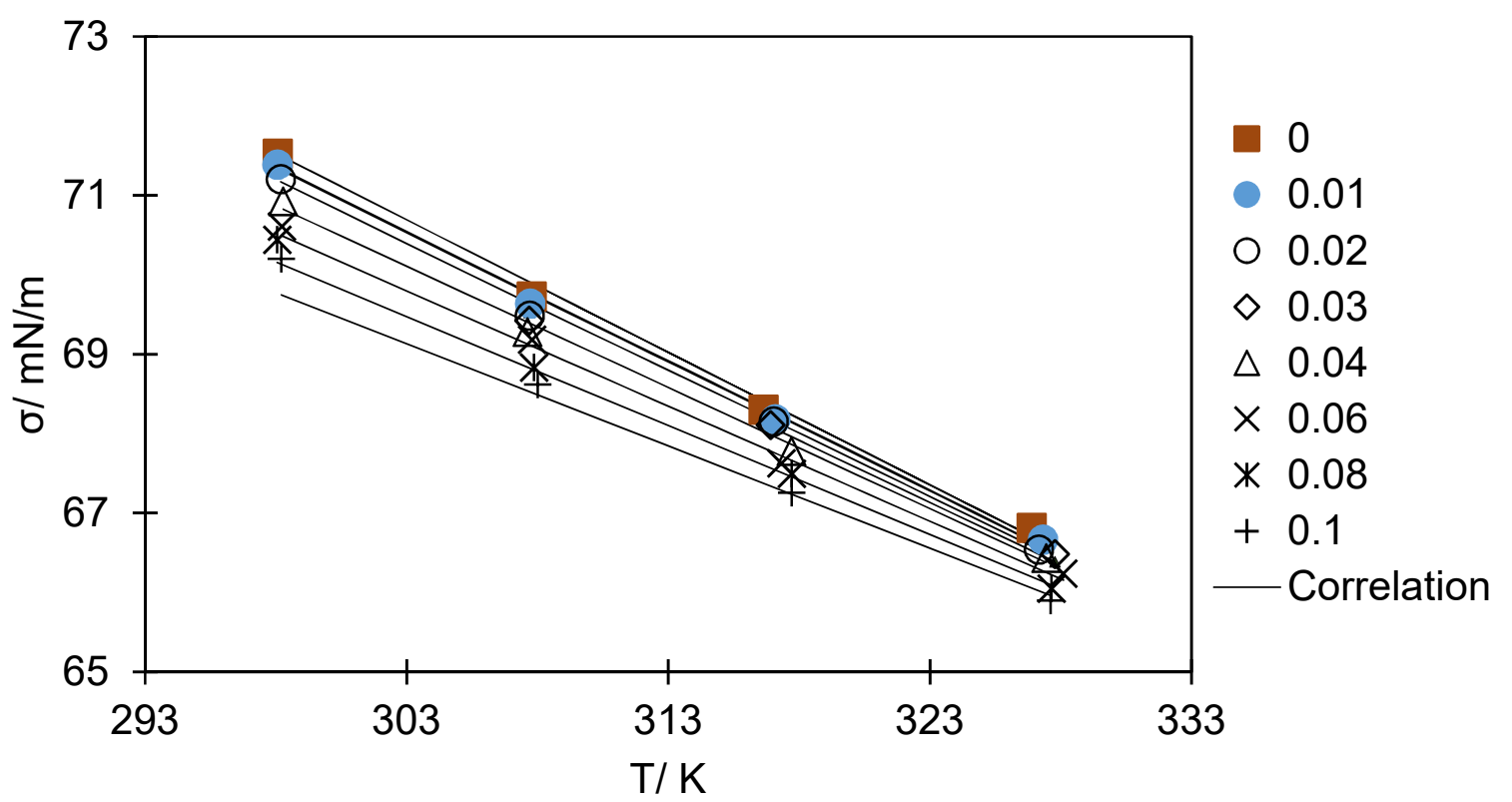

Figure 5: Temperature $T$ effect on surface tension $\sigma$ of DL-malic at different concentrations $w / \%$, the fitted line is from correlation and statistical results from correlation analysis are listed in Table 11.

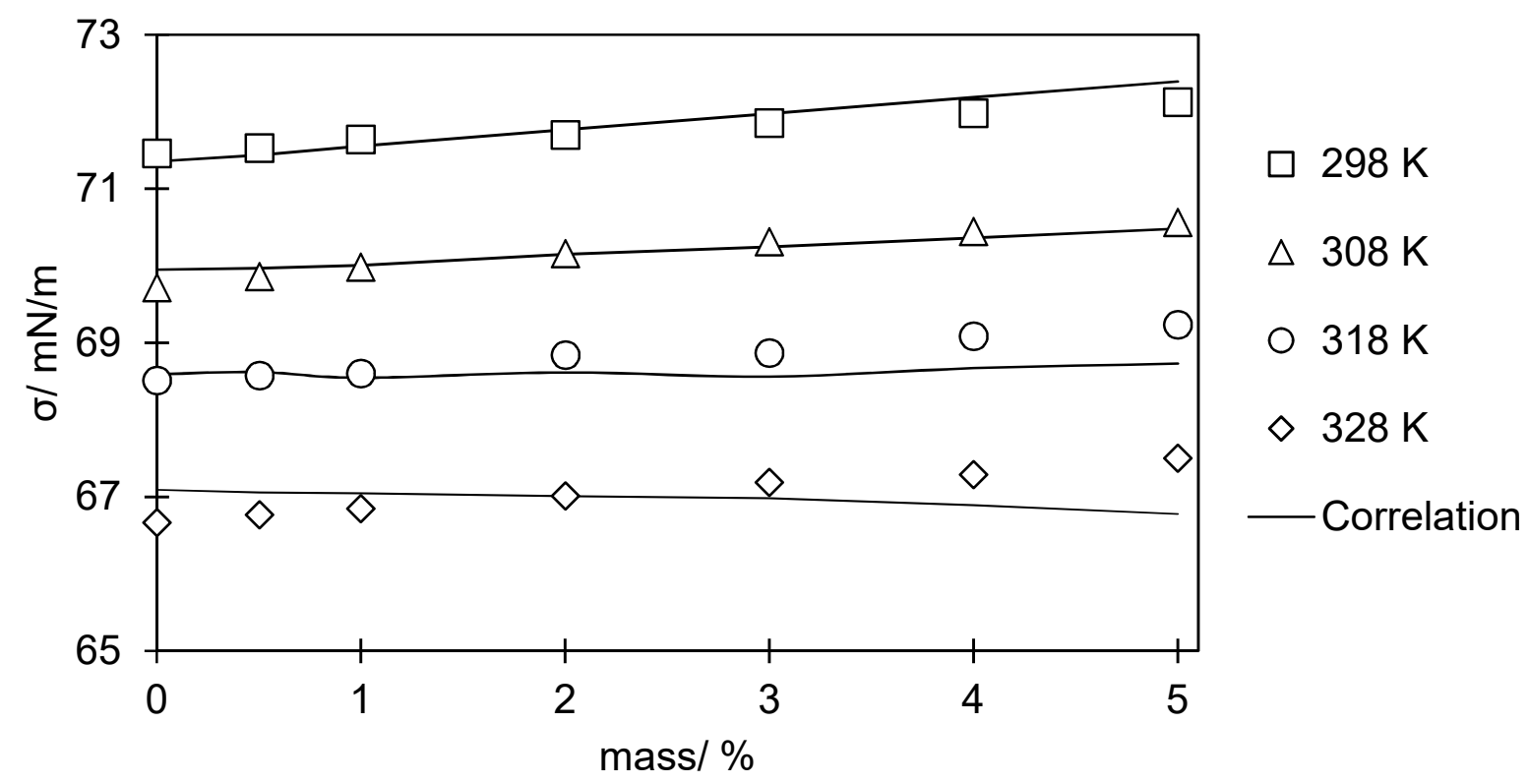

Figure 6: Concentration $w / \%$ effect on surface tension $\sigma$ of L-serine from $T=(298-$ $328) \mathrm{K}$ at $p=101 \mathrm{kPa}$, the fitted line is from correlation and statistical results from correlation analysis are listed in Table 11. 


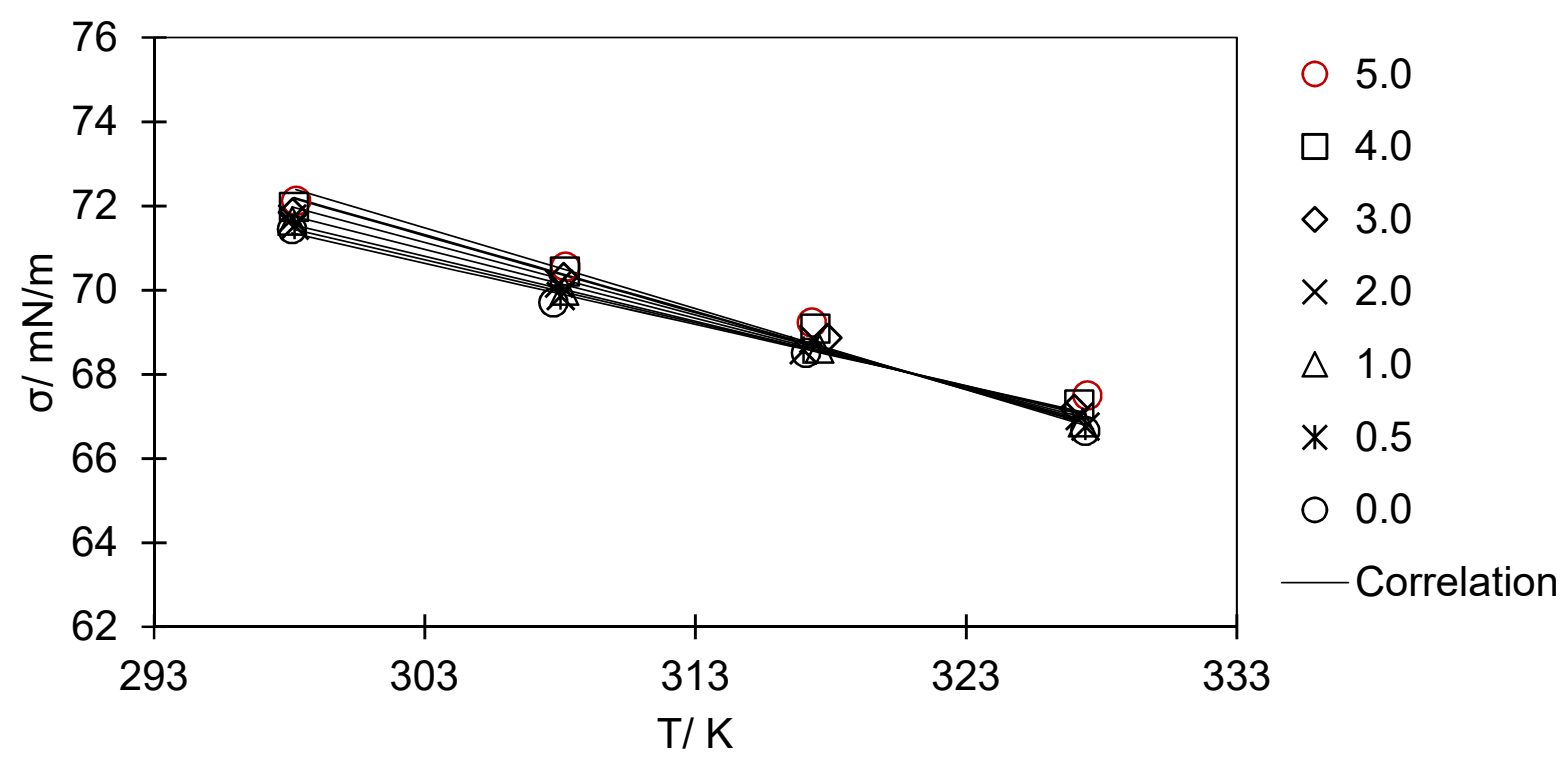

Figure 7: Temperature $T$ effect on surface tension $\sigma$ of L-serine at different concentrations $w / \%$, the fitted line is from correlation and statistical results from correlation analysis are listed in Table 11.

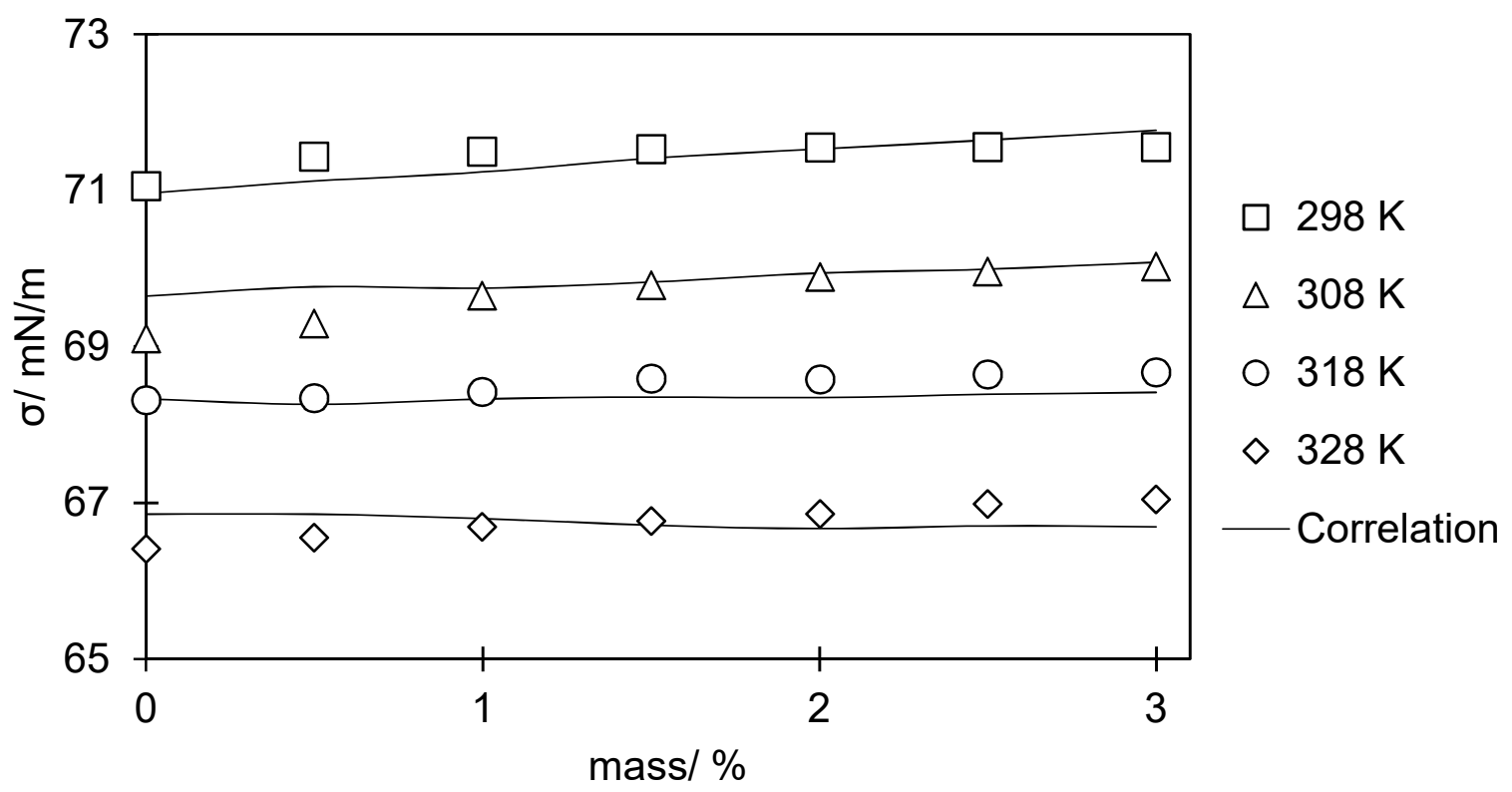

Figure 8: Concentration $w / \%$ effect on surface tension $\sigma$ of L-glutamine from $\mathrm{T}=(298$ -328) $\mathrm{K}$ at $p=101 \mathrm{kPa}$, the fitted line is from correlation and statistical results from correlation analysis are listed in Table 11. 


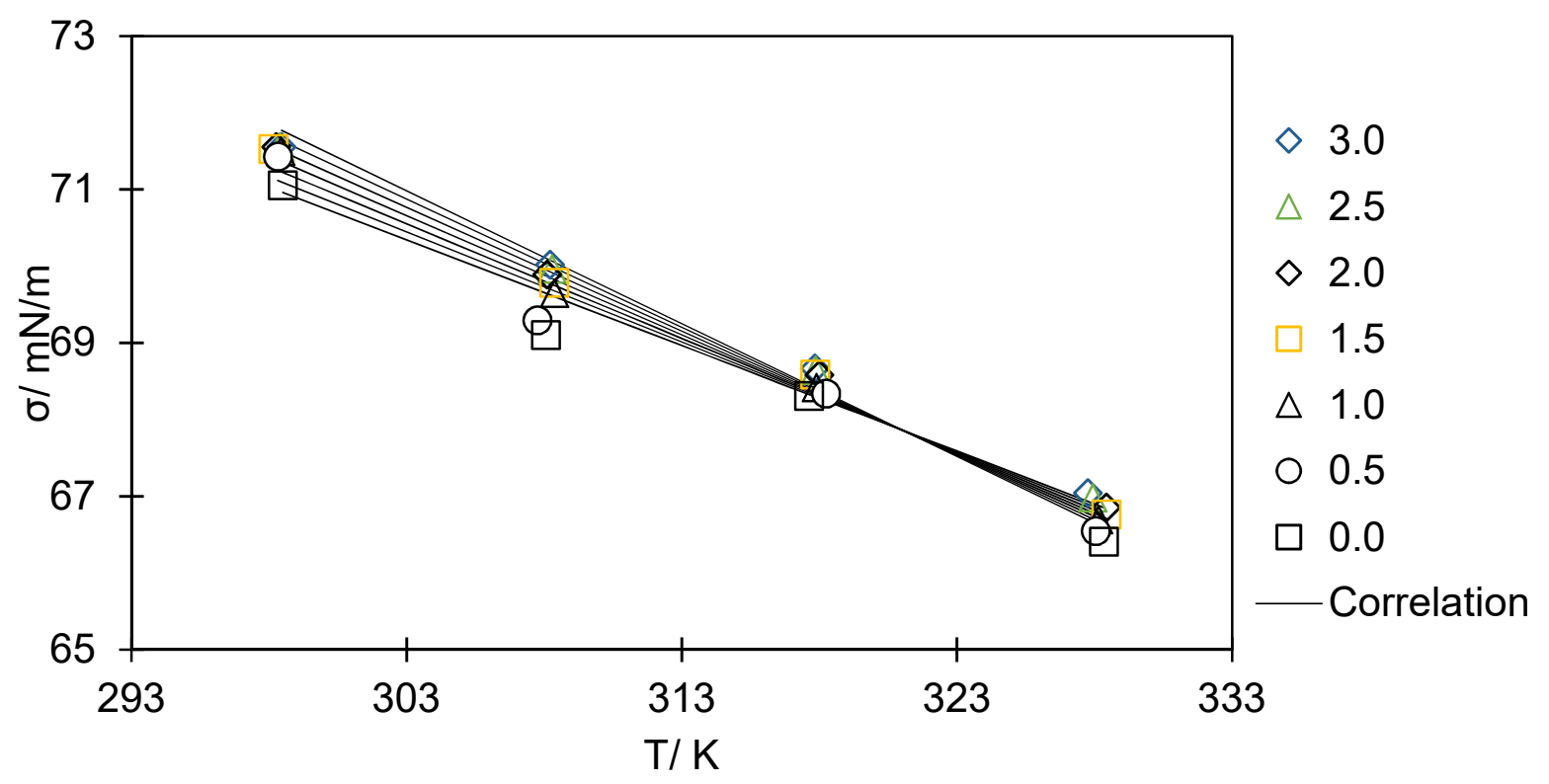

Figure 9: Temperature $T$ effect on surface tension $\sigma$ of L-glutamine at different concentrations $w / \%$, the fitted line is from correlation and statistical results from correlation analysis are listed in Table 11.

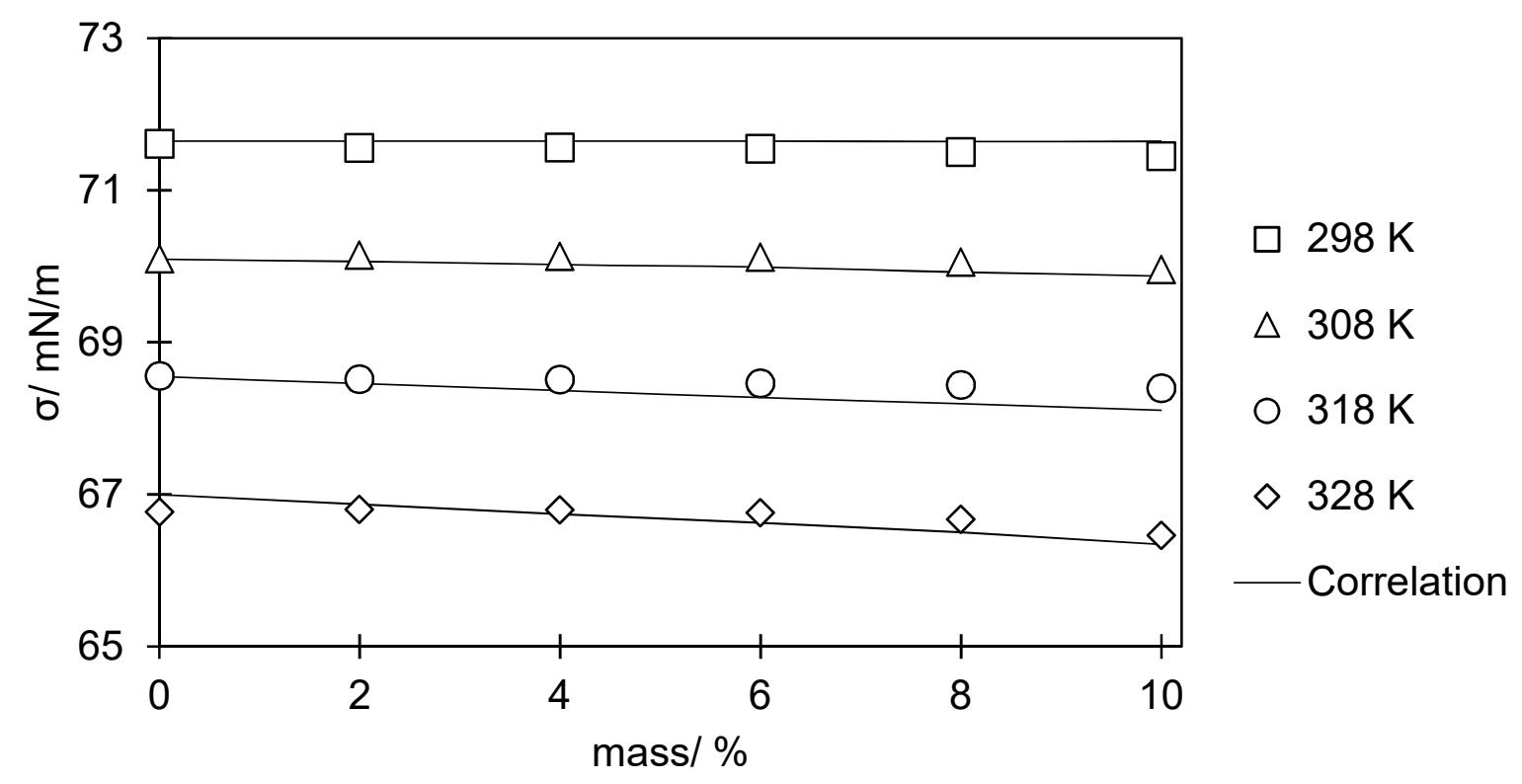

Figure 10: Concentration $w / \%$ effect on surface tension $\sigma$ of L-proline from $T=(298$ $-328) \mathrm{K}$ at $p=101 \mathrm{kPa}$, the fitted line is from correlation and statistical results from correlation analysis are listed in Table 11. 


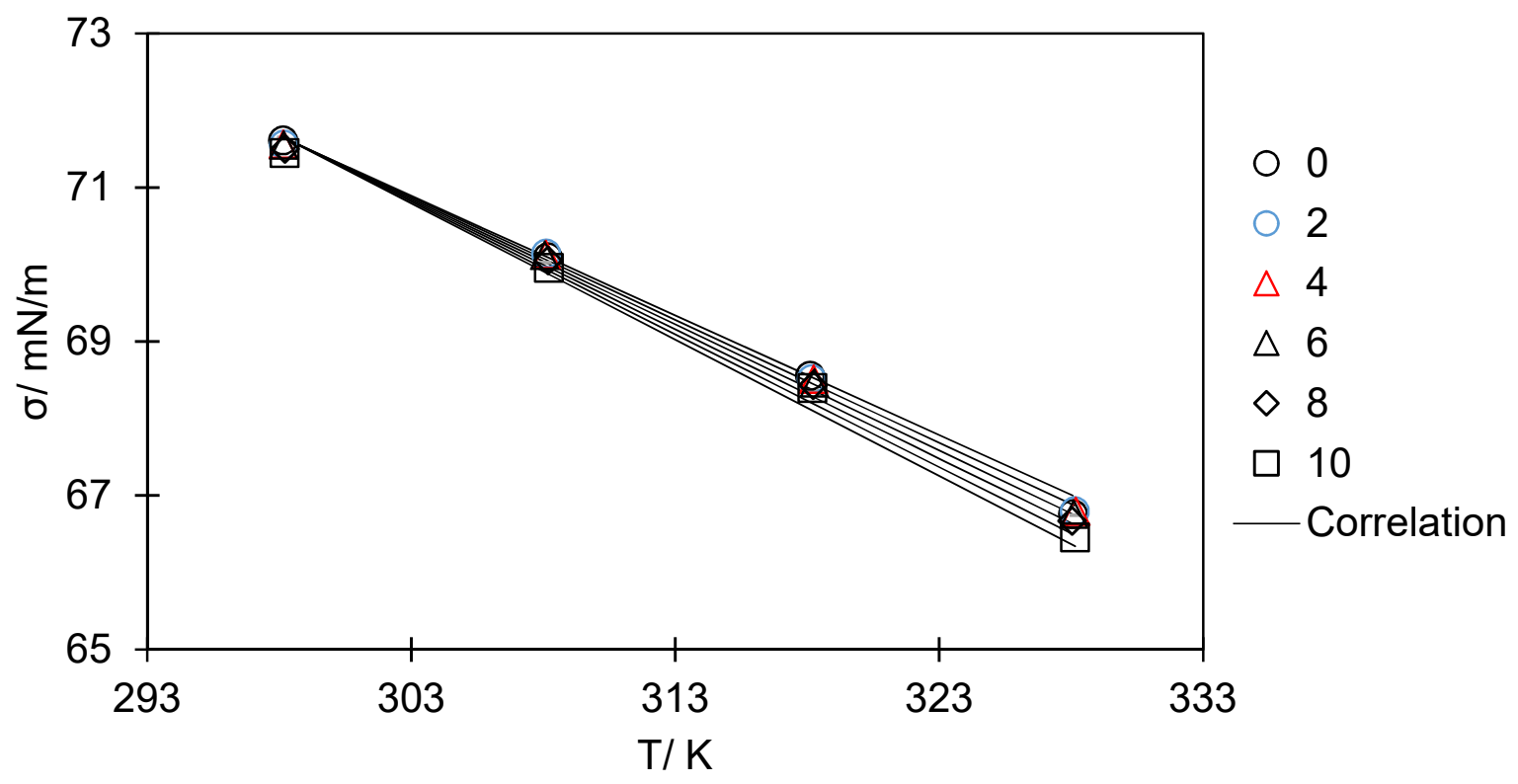

Figure 11: Temperature $T$ effect on surface tension $\sigma$ of L-proline at different concentrations $w / \%$, the fitted line is from correlation and statistical results from correlation analysis are listed in Table 11.

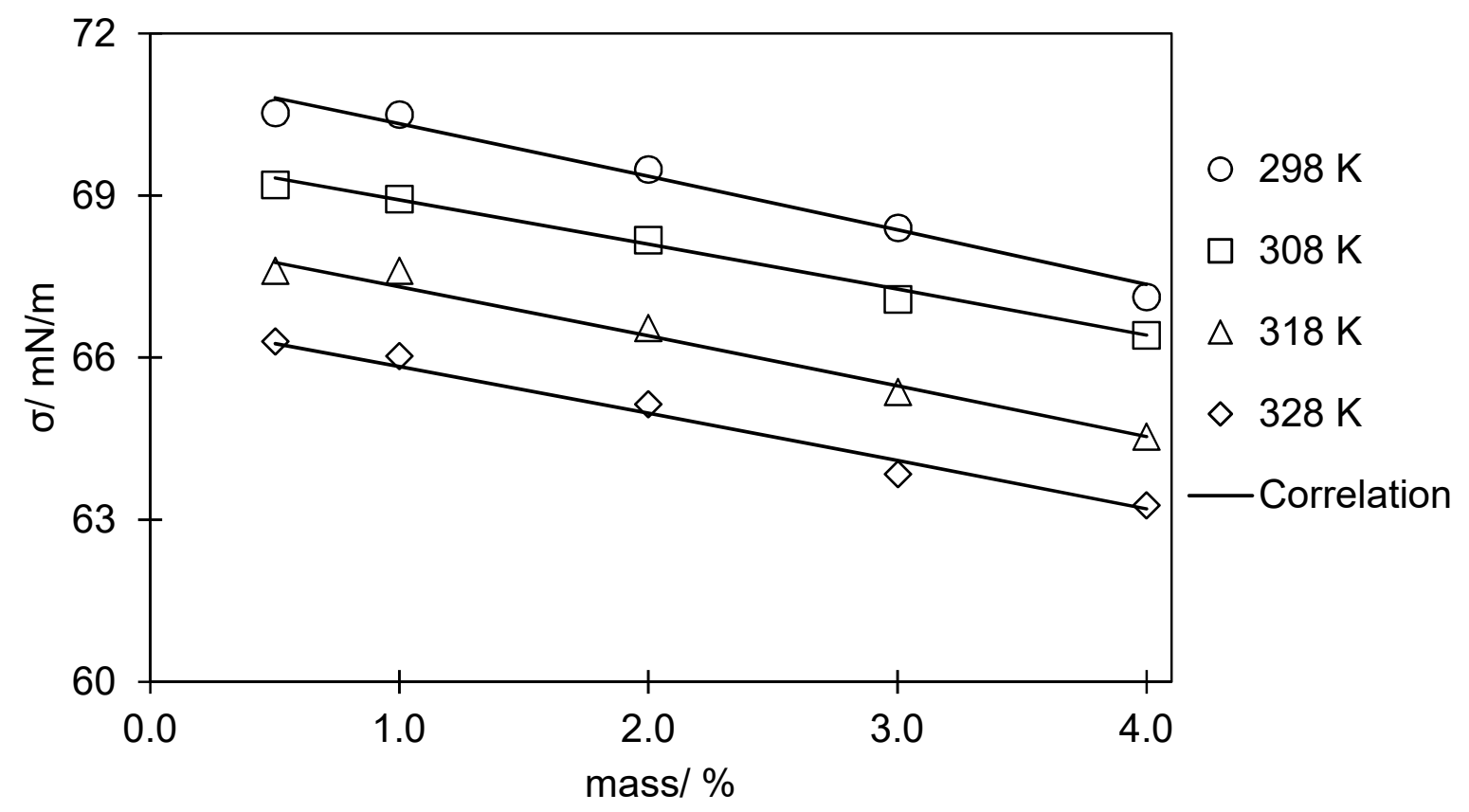

Figure 12: Concentration $w / \%$ effect on surface tension $\sigma$ of $L$-valine from $T=(298-$ $328) \mathrm{K}$ at $p=101 \mathrm{kPa}$, the fitted line is from correlation and statistical results from correlation analysis are listed in Table 11. 


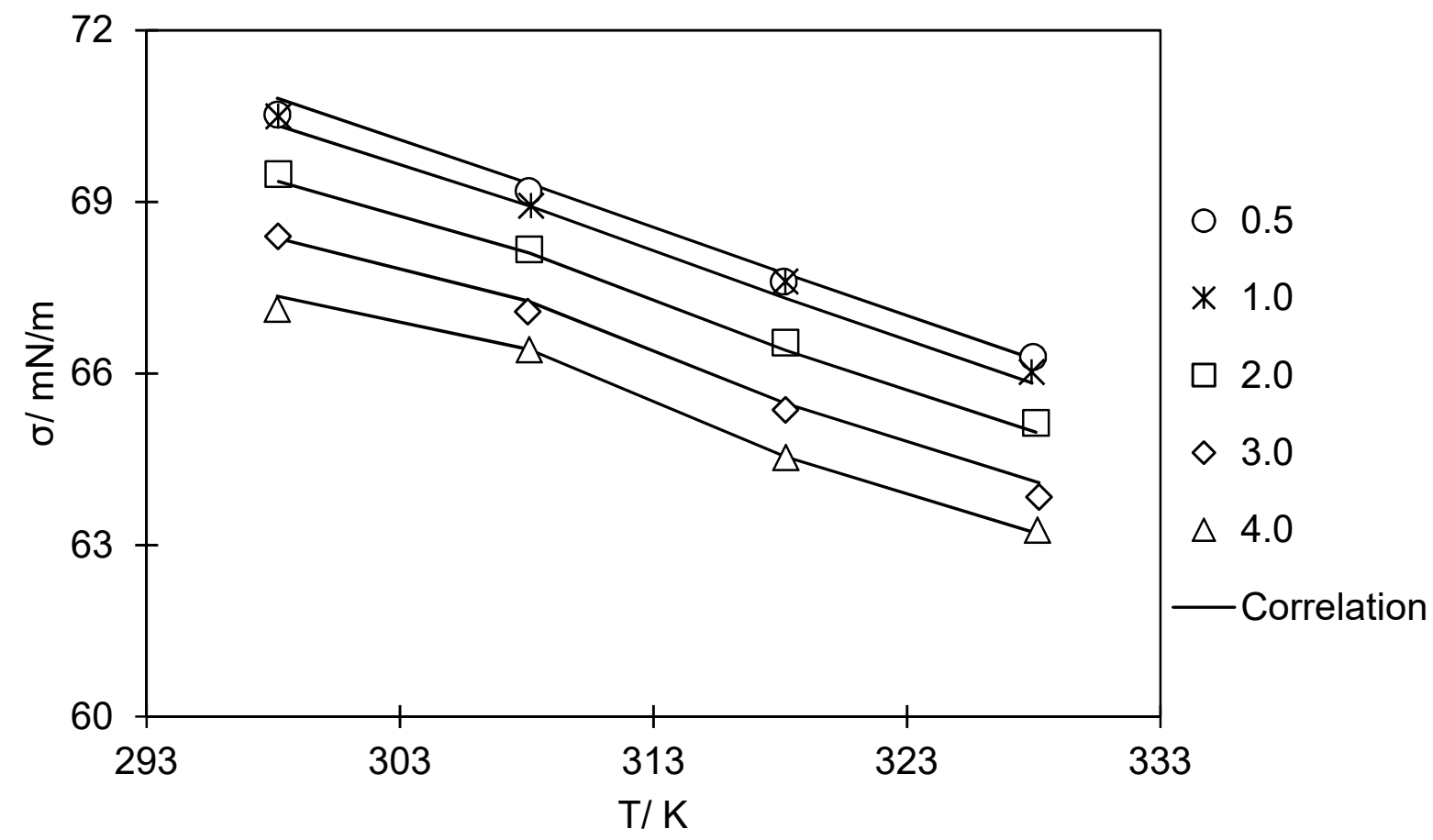

Figure 13: Temperature $T$ effect on surface tension $\sigma$ of L-valine at different concentrations $w / \%$, the fitted line is from correlation and statistical results from correlation analysis are listed in Table 11.

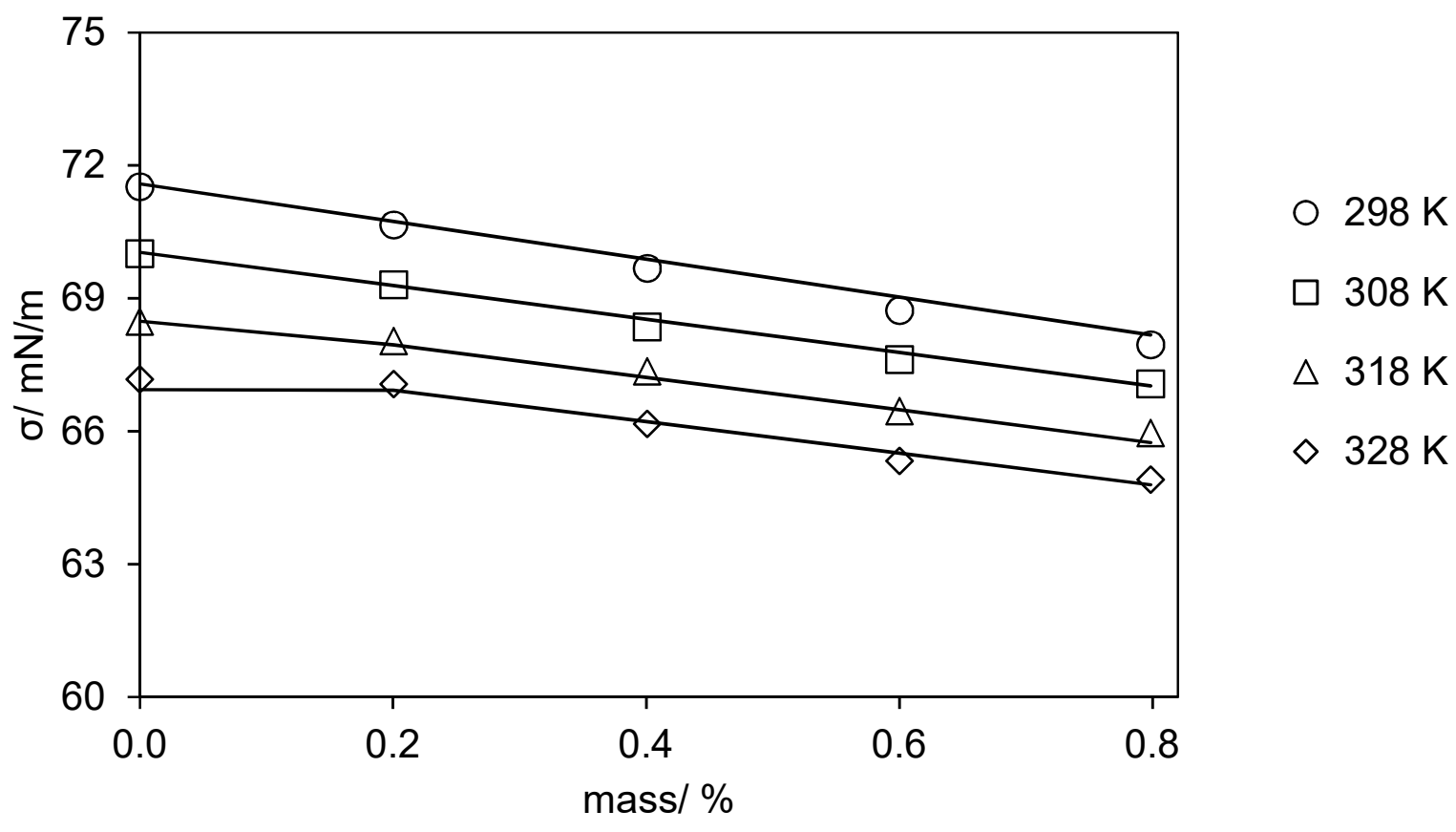

Figure 14: Concentration $w / \%$ effect on surface tension $\sigma$ of L-lactic acid from $T=$ $(298-328) \mathrm{K}$ at $p=101 \mathrm{kPa}$, the fitted line is from correlation and statistical results from correlation analysis are listed in Table 11. 


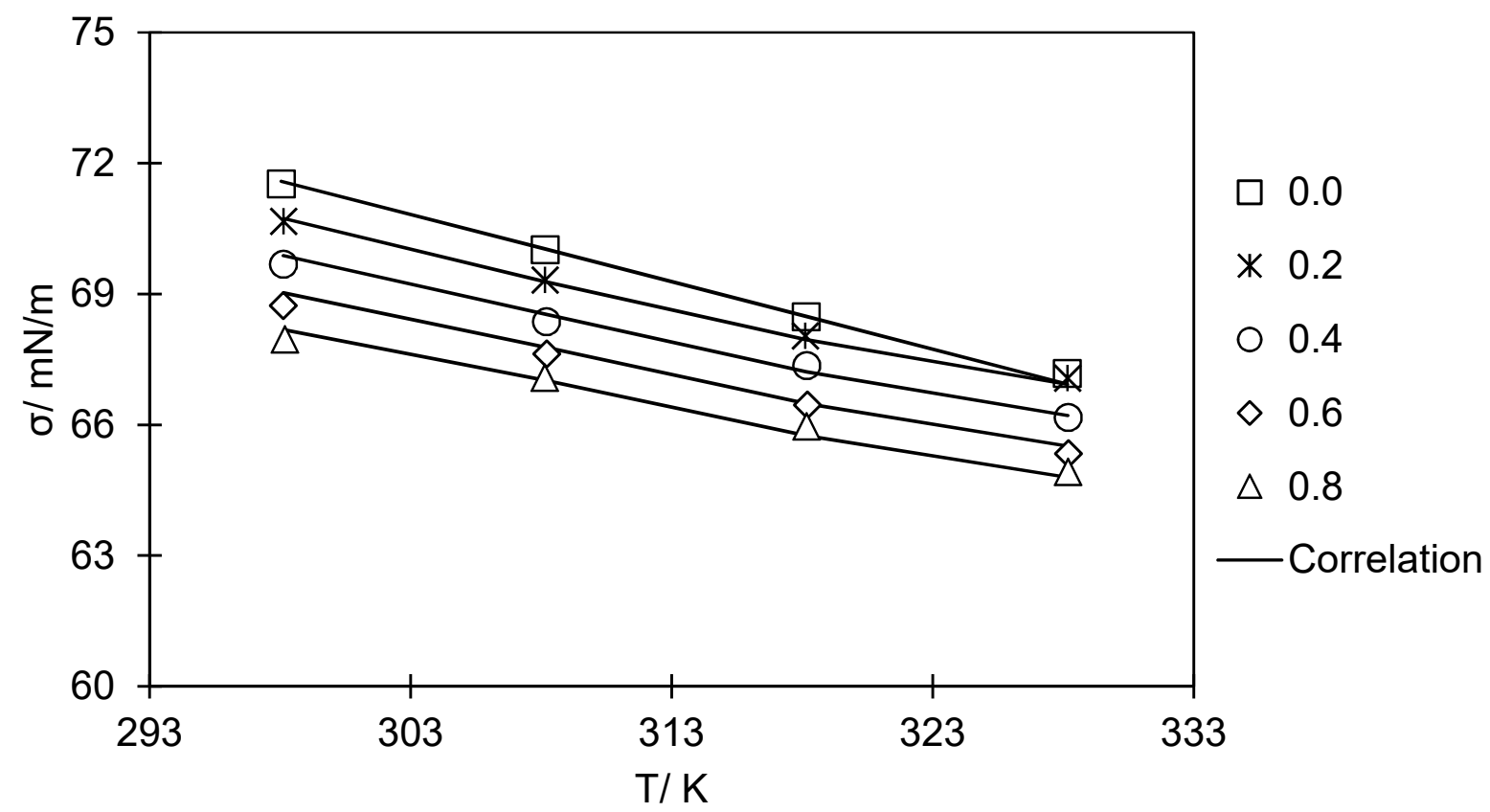

Figure 15: Temperature $T$ effect on surface tension $\sigma$ of L-lactic acid at different concentrations $w / \%$, the fitted line is from correlation and statistical results from correlation analysis are listed in Table 11. 
Table 1: Details of the ethanol, amino acids and malic acid used in this work.

\begin{tabular}{ccccc}
\hline product & CAS no. & structural formula & purity (wt \%) & source \\
\hline Ethanol & $64-17-5$ & $99.9 \%$ & $\begin{array}{c}\text { Denaturants } \\
\text { Ltd. }\end{array}$ \\
L-glutamine & $56-85-9$ & & Sigma - \\
Aldrich
\end{tabular}

Table 2: Experimental values of Surface tension $\sigma$ of aqueous solutions of ethanol as a function of percentage mass fraction $w / \%$ at $T=(298$ and, 313) $\mathrm{K}$ and pressure $p$ $=101 \mathrm{kPa}{ }^{\mathrm{a}}$.

\begin{tabular}{ccccc}
\hline mass fraction & \multicolumn{2}{c}{$\sigma$ measured $/ \mathrm{mN} / \mathrm{m}$} & \multicolumn{2}{c}{$\sigma$ literature $/ \mathrm{mN} / \mathrm{m}$} \\
\hline$w / \%$ & $298 / \mathrm{K}$ & $313 / \mathrm{K}$ & $298 / \mathrm{K}$ & $313 / \mathrm{K}$ \\
\hline 0 & 72.04 & 69.89 & 72.01 & 69.52 \\
5 & 55.14 & 53.13 & 55.73 & 53.63 \\
10 & 47.34 & 45.92 & 47.53 & 45.58 \\
15 & 41.96 & 40.41 & 42.08 & 40.27 \\
20 & 38.20 & 36.71 & 37.97 & 36.28
\end{tabular}

a Standard uncertainty are $\mathrm{u}(T)=0.1 \mathrm{~K}, \mathrm{u}(p)=1 \mathrm{kPa}$ and $\mathrm{u}(w)=0.0001 \mathrm{~g}$. Expanded uncertainty for $\sigma$ is $\mathrm{U}(\sigma)=0.06 \mathrm{mN} / \mathrm{m}$ (0.95 level of confidence). 
Table 3: Experimental values of Surface tension $\sigma$ of aqueous solutions of $L$ glutamine as a function of percentage mass fraction $w / \%$ at $T=(298,308,318$, and, 328) $\mathrm{K}$ and pressure $p=101 \mathrm{kPa}$.

\begin{tabular}{ccccc}
\hline mass fraction & \multicolumn{3}{c}{$\sigma / \mathrm{mN} / \mathrm{m}$} \\
\hline$w / \%$ & $298 / \mathrm{K}$ & $308 / \mathrm{K}$ & $318 / \mathrm{K}$ & $328 / \mathrm{K}$ \\
\hline 0 & 71.06 & 69.10 & 68.31 & 66.41 \\
0.499 & 71.43 & 69.29 & 68.34 & 66.55 \\
0.998 & 71.49 & 69.65 & 68.42 & 66.69 \\
1.501 & 71.53 & 69.78 & 68.59 & 66.76 \\
2.001 & 71.55 & 69.89 & 68.58 & 66.85 \\
2.499 & 71.55 & 69.96 & 68.64 & 66.98 \\
2.999 & 71.55 & 70.02 & 68.67 & 67.04
\end{tabular}

a Standard uncertainty are $\mathrm{u}(T)=0.1 \mathrm{~K}, \mathrm{u}(p)=1 \mathrm{kPa}$ and $\mathrm{u}(w)=0.00005 \mathrm{~g}$. Expanded uncertainty for $\sigma$ is $U(\sigma)=0.1 \mathrm{mN} / \mathrm{m}$ ( 0.95 level of confidence).

Table 4: Experimental values of Surface tension $\sigma$ of aqueous solutions of L-serine as a function of percentage mass fraction $w / \%$ at $T=(298,308,318$, and, 328) $\mathrm{K}$ and pressure $p=101 \mathrm{kPa}^{\mathrm{a}}$.

\begin{tabular}{ccccc}
\hline mass fraction & \multicolumn{4}{c}{$\sigma / \mathrm{mN} / \mathrm{m}$} \\
\hline$w / \%$ & $298 / \mathrm{K}$ & $308 / \mathrm{K}$ & $318 / \mathrm{K}$ & $328 / \mathrm{K}$ \\
\hline 0 & 71.46 & 69.71 & 68.51 & 66.66 \\
0.504 & 71.53 & 69.85 & 68.58 & 66.76 \\
1.000 & 71.64 & 69.98 & 68.60 & 66.84 \\
2.001 & 71.70 & 70.15 & 68.84 & 67.01 \\
3.000 & 71.85 & 70.31 & 68.87 & 67.19 \\
3.999 & 71.98 & 70.44 & 69.09 & 67.28 \\
5.000 & 72.12 & 70.56 & 69.23 & 67.50
\end{tabular}

a Standard uncertainty are $\mathrm{u}(T)=0.1 \mathrm{~K}, \mathrm{u}(p)=1 \mathrm{kPa}$ and $\mathrm{u}(w)=0.00005 \mathrm{~g}$. Expanded uncertainty for $\sigma$ is $U(\sigma)=0.06 \mathrm{mN} / \mathrm{m}$ (0.95 level of confidence). 
Table 5 : Experimental values of Surface tension $\sigma$ of aqueous solutions of Lmethionine as a function of percentage mass fraction $w / \%$ at $T=(298,308,318$, and, 328) $\mathrm{K}$ and pressure $p=101 \mathrm{kPa}$ a.

\begin{tabular}{ccccc}
\hline mass fraction & \multicolumn{4}{c}{$\sigma / \mathrm{mN} / \mathrm{m}$} \\
\hline$w / \%$ & $298 / \mathrm{K}$ & $308 / \mathrm{K}$ & $318 / \mathrm{K}$ & $328 / \mathrm{K}$ \\
\hline 0 & 71.52 & 69.94 & 68.54 & 66.78 \\
0.500 & 71.39 & 69.89 & 68.40 & 66.65 \\
1.000 & 71.30 & 69.69 & 68.30 & 66.56 \\
2.000 & 71.02 & 69.45 & 68.06 & 66.32 \\
3.000 & 70.77 & 69.15 & 67.74 & 65.78 \\
4.001 & 70.61 & 68.90 & 67.28 & 64.97
\end{tabular}

a Standard uncertainty are $\mathrm{u}(T)=0.1 \mathrm{~K}, \mathrm{u}(p)=1 \mathrm{kPa}$ and $\mathrm{u}(w)=0.00002 \mathrm{~g}$. Expanded uncertainty for $\sigma$ is $\mathrm{U}(\sigma)=0.06 \mathrm{mN} / \mathrm{m}$ (0.95 level of confidence).

Table 6 : Experimental values of Surface tension $\sigma$ of aqueous solutions of L-proline as a function of percentage mass fraction $w / \%$ at $T=(298,308,318$, and, 328$) \mathrm{K}$ and pressure $p=101 \mathrm{kPa}$.

\begin{tabular}{ccccc}
\hline mass fraction & \multicolumn{4}{c}{$\sigma / \mathrm{mN} / \mathrm{m}$} \\
\hline$w / \%$ & $298 / \mathrm{K}$ & $308 / \mathrm{K}$ & $318 / \mathrm{K}$ & $328 / \mathrm{K}$ \\
\hline 0 & 71.61 & 70.10 & 68.56 & 66.76 \\
1.996 & 71.56 & 70.14 & 68.51 & 66.80 \\
3.996 & 71.56 & 70.13 & 68.51 & 66.79 \\
5.995 & 71.55 & 70.12 & 68.46 & 66.75 \\
7.996 & 71.50 & 70.05 & 68.44 & 66.67 \\
9.995 & 71.45 & 69.95 & 68.40 & 66.46 \\
\hline
\end{tabular}

a Standard uncertainty are $\mathrm{u}(T)=0.1 \mathrm{~K}, \mathrm{u}(p)=1 \mathrm{kPa}$ and $\mathrm{u}(w)=0.00005 \mathrm{~g}$. Expanded uncertainty for $\sigma$ is $U(\sigma)=0.04 \mathrm{mN} / \mathrm{m}$ (0.95 level of confidence). 
Table 7: Experimental values of Surface tension $\sigma$ of aqueous solutions of DL-malic acid as a function of percentage mass fraction $w / \%$ at $T=(298,308,318$, and, 328) $\mathrm{K}$ and pressure $p=101 \mathrm{kPa}$.

\begin{tabular}{ccccc}
\hline mass fraction & \multicolumn{4}{c}{$\sigma / \mathrm{mN} / \mathrm{m}$} \\
\hline$w / \%$ & $298 / \mathrm{K}$ & $308 / \mathrm{K}$ & $318 / \mathrm{K}$ & $328 / \mathrm{K}$ \\
\hline 0 & 71.52 & 69.73 & 68.30 & 66.81 \\
1.049 & 71.39 & 69.64 & 68.16 & 66.67 \\
2.026 & 71.20 & 69.49 & 68.16 & 66.54 \\
3.004 & 71.09 & 69.42 & 68.11 & 66.48 \\
4.002 & 70.92 & 69.28 & 67.78 & 66.43 \\
6.001 & 70.61 & 69.18 & 67.63 & 66.24 \\
7.998 & 70.44 & 68.83 & 67.49 & 66.05 \\
10.001 & 70.20 & 68.62 & 67.25 & 65.89
\end{tabular}

a Standard uncertainty are $\mathrm{u}(T)=0.1 \mathrm{~K}, \mathrm{u}(p)=1 \mathrm{kPa}$ and $\mathrm{u}(w)=0.0005 \mathrm{~g}$. Expanded uncertainty for $\sigma$ is $U(\sigma)=0.05 \mathrm{mN} / \mathrm{m}$ ( 0.95 level of confidence).

Table 8: Experimental values of Surface tension $\sigma$ of aqueous solutions of L-valine as a function of percentage mass fraction $w / \%$ at $T=(298,308,318$, and, 328) $\mathrm{K}$ and pressure $p=101 \mathrm{kPa}$.

\begin{tabular}{ccccc}
\hline mass fraction & \multicolumn{4}{c}{$\sigma / \mathrm{mN} / \mathrm{m}$} \\
\hline$w / \%$ & $298 / \mathrm{K}$ & $308 / \mathrm{K}$ & $318 / \mathrm{K}$ & $328 / \mathrm{K}$ \\
\hline 0.502 & 70.53 & 69.19 & 67.61 & 66.30 \\
1.000 & 70.50 & 68.93 & 67.61 & 66.02 \\
1.999 & 69.48 & 68.17 & 66.54 & 65.14 \\
3.001 & 68.40 & 67.08 & 65.36 & 63.84 \\
4.000 & 67.12 & 66.41 & 64.53 & 63.26
\end{tabular}

a Standard uncertainty are $\mathrm{u}(T)=0.1 \mathrm{~K}, \mathrm{u}(p)=1 \mathrm{kPa}$ and $\mathrm{u}(w)=0.00002 \mathrm{~g}$. Expanded uncertainty for $\sigma$ is $U(\sigma)=0.1 \mathrm{mN} / \mathrm{m}$ (0.95 level of confidence). 
Table 9: Experimental values of Surface tension $\sigma$ of aqueous solutions of L-lactic acid as a function of percentage mass fraction $w / \%$ at $T=(298,308,318$, and, 328) $\mathrm{K}$ and pressure $p=101 \mathrm{kPa}$.

\begin{tabular}{ccccc}
\hline mass fraction & \multicolumn{4}{c}{$\sigma / \mathrm{mN} / \mathrm{m}$} \\
\hline$w / \%$ & $298 / \mathrm{K}$ & $308 / \mathrm{K}$ & $318 / \mathrm{K}$ & $328 / \mathrm{K}$ \\
\hline 0 & 71.53 & 70.02 & 68.48 & 67.18 \\
0.200 & 70.66 & 69.32 & 68.04 & 67.07 \\
0.401 & 69.69 & 68.36 & 67.36 & 66.17 \\
0.600 & 68.73 & 67.63 & 66.46 & 65.34 \\
0.799 & 67.69 & 67.06 & 65.96 & 64.92
\end{tabular}

a Standard uncertainty are $\mathrm{u}(T)=0.1 \mathrm{~K}, \mathrm{u}(p)=1 \mathrm{kPa}$ and $\mathrm{u}(w)=0.00002 \mathrm{~g}$. Expanded uncertainty for $\sigma$ is $U(\sigma)=0.02 \mathrm{mN} / \mathrm{m}$ (0.95 level of confidence).

Table 10: Slope of surface tension $\sigma$ of aqueous solution of the organic acids studied in this work as a function of temperature $T$ and pressure $p=101 \mathrm{kPa}$ a.

\begin{tabular}{cccccccc}
\hline T/K & $\begin{array}{c}\text { methioni } \\
\text { ne/ } \\
\mathrm{mN} / \mathrm{m}\end{array}$ & $\begin{array}{c}\text { DL- } \\
\text { malic } \\
\mathrm{mN} / \mathrm{m} /\end{array}$ & $\begin{array}{c}\mathrm{L}- \\
\text { serine/ } \\
\mathrm{mN} / \mathrm{m}\end{array}$ & $\begin{array}{c}\mathrm{L}- \\
\text { glutamin } \\
\mathrm{e} / \mathrm{mN} / \mathrm{m}\end{array}$ & $\begin{array}{c}\mathrm{L}- \\
\text { proline/ } \\
\mathrm{mN} / \mathrm{m}\end{array}$ & $\begin{array}{c}\text { L-valine/ } \\
\mathrm{mN} / \mathrm{m}\end{array}$ & $\begin{array}{c}\text { L-lactic } \\
\text { acid/ } \\
\mathrm{mN} / \mathrm{m}\end{array}$ \\
\hline 298 & -0.2352 & -0.1342 & 0.1289 & 0.128 & -0.0144 & -1.0065 & -4.5522 \\
308 & -0.2705 & -0.1219 & 0.1658 & 0.3012 & -0.0142 & -0.8287 & -3.7479 \\
318 & -0.3034 & -0.1071 & 0.1446 & 0.1309 & -0.0153 & -0.9462 & -3.5809 \\
328 & -0.4312 & -0.0885 & 0.1620 & 0.2091 & -0.0281 & -0.9231 & -3.6574
\end{tabular}

a Standard uncertainty are $\mathrm{u}(T)=0.1 \mathrm{~K}, \mathrm{u}(p)=1 \mathrm{kPa}$ and $\mathrm{u}(w)=0.00002 \mathrm{~g}$. 
Table 11: Coefficients and deviations of the present correlation.

\begin{tabular}{cccccccc}
\hline & $\begin{array}{c}\text { L- } \\
\text { methioni } \\
\text { ne }\end{array}$ & $\begin{array}{c}\text { DL- } \\
\text { malic } \\
\text { acid }\end{array}$ & $\begin{array}{c}\text { L-serine } \\
\text { glutamin } \\
\text { e }\end{array}$ & $\begin{array}{c}\text { L- } \\
\text { proline }\end{array}$ & L-valine & $\begin{array}{c}\text { L-lactic } \\
\text { acid }\end{array}$ \\
\hline $\begin{array}{c}\mathrm{a} / \mathrm{mN} / \mathrm{m} \\
\mathrm{b} /\end{array}$ & 116.5 & 121.2 & 114.7 & 112.1 & 118.0 & 118.175 & 118.25 \\
$\mathrm{mN} / \mathrm{m} . \mathrm{K}$ & -0.1508 & -0.1667 & -0.1456 & -0.1377 & -0.1554 & -0.1571 & -0.1550 \\
$\mathrm{c} / \mathrm{mN} / \mathrm{m}$ & 24.29 & -15.73 & 29.87 & 53.95 & 6.691 & -591.25 & -1928.7 \\
$\mathrm{~d} /$ & -0.0917 & 0.04572 & -0.0930 & -0.1681 & -0.0224 & 0.0833 & 0.09475 \\
$\mathrm{mN} / \mathrm{m} . \mathrm{K}$ & 1 & & & & & & \\
\hline $\mathrm{AARD}$ & $0.14 \%$ & $0.16 \%$ & $0.33 \%$ & $0.27 \%$ & $0.22 \%$ & $0.21 \%$ & $0.20 \%$ \\
$\mathrm{MARD}$ & $0.59 \%$ & $0.98 \%$ & $1.07 \%$ & $0.79 \%$ & $0.96 \%$ & $0.40 \%$ & $0.62 \%$ \\
\hline
\end{tabular}

Table 12: Experimental values of Density $\rho$ and $p H$ of initial aqueous concentration of amino and organic acids studied in this work as a function of percentage mass fraction $w / \%$ at temperature $T=298 \mathrm{~K}$ and pressure $p=101 \mathrm{kPa}$.

\begin{tabular}{|c|c|c|c|}
\hline Acid name & mass fraction/ $w \%$ & $\rho /{\mathrm{g} . \mathrm{cm}^{-3}}^{-3}$ & $p H$ \\
\hline L-glutamine & 0.5 & 0.9988 & 4.34 \\
\hline L-serine & 0.5 & 0.9991 & 5.82 \\
\hline L-methionine & 0.5 & 0.9985 & 5.05 \\
\hline L-proline & 2.0 & 1.0026 & 6.45 \\
\hline DL-malic acid & 1.0 & 1.0008 & 2.27 \\
\hline L-valine & 0.5 & 0.9981 & 5.91 \\
\hline L-lactic acid & 1.0 & 0.9995 & 2.26 \\
\hline
\end{tabular}




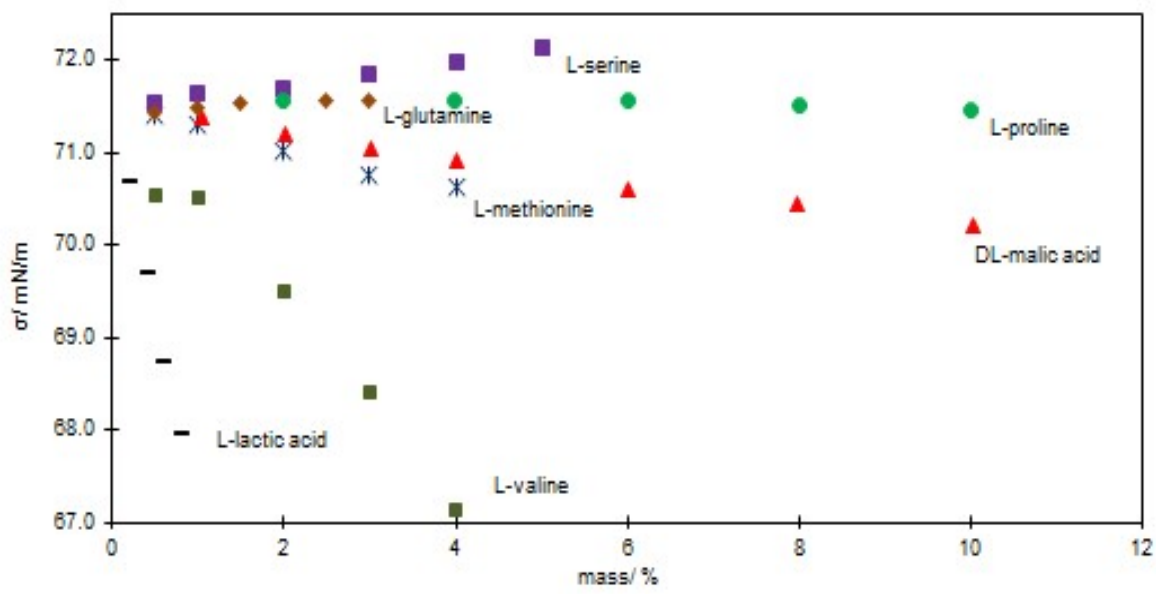

Figure TOC: For Table of Contents Only 